\title{
A Brief Analysis of Innovative Spirit and Practical Ability Training in Junior High School Mathematics Teaching
}

\author{
Xia ZHAO \\ School of information engineering, Nanjing xiaozhuang university, Nanjing, P.R.China 210017 \\ email:244593412@qq.com
}

Key words: Junior high school mathematics teaching, innovative spirit, practical ability

\begin{abstract}
Effective methods of training innovative spirit and practical ability in junior high school mathematics teaching are as follows: creating independent learning situation, building pleasant teaching atmosphere, cultivating students' sense of success, constructing effective problem contexts, encouraging reasonable partner study, and advocating diversified self-evaluations.
\end{abstract}

\section{Introduction}

The international community development in the $21^{\text {st }}$ century is characterized by high speed, comprehensiveness, rationality and diversification. Whoever has high-tech and innovative knowledge, especially innovative talents, is leading development. Only when plenty of innovative talents are trained can varied problems arising from social development can be solved, social and economic sustainable development be ensured, and furthermore human long-term development guaranteed from the source. WANG Zhan clearly stated in Establishment of Basic Educational Curriculum System with Chinese Characteristics that the new curriculum shall "focus on innovative spirit and practical ability training, establish new teaching methods and promote reform in ways of learning”

\section{Theoretical Studies on Students' Innovative Spirit and Practical Ability Training in Junior High School Mathematics Teaching}

\subsection{Basic Theories of Junior High School Mathematics Teaching Process}

\subsubsection{Developmental Teaching Theory}

Developmental teaching theory came into being in early 1950s and was gradually built by Zakov based on his teaching experience. Its fundamental instruction ideology is "promoting students' general development with the best effect", i.e. "making systematic and purposeful efforts in students' development" so as to facilitate overall development of students. Zakov combined his years' experimental teaching experience to summarize five teaching principles, including high speed, high difficulty, making students understand the teaching process, making all students (including those with poor academic performance) develop and letting theoretical knowledge take the lead.

\subsubsection{Cognitive Learning Theory}

Cognitive learning theory derived from the insight theory of Gestalt psychology (early representative school of the cognitive theory) and its main ideas include: the process of human information acquisition is the information exchange process of perceiving, noting, memorizing, understanding and solving problems; people's cognition, notice and understanding are selective and they are subjects of cognitive learning; initiative learning and learning quality are determined by effect, etc. It mainly refers to a learning theory of exploring learning patterns through people's cognitive process. Our teaching process shall start with students' comprehensive qualities and overall development, take full into account students' future development and lay a solid foundation for students' overall development.

\subsubsection{Constructivism Learning Theory}

It's been two decades since emergence of the constructivism learning theory which is a new 
cognitive theory. Compared with behaviorism and cognitivism, constructivism pays more attention to how learners build their unique spiritual world with their original experience, psychological structure and beliefs. On the basis of such cognitive theory, constructivism has gradually formed its own characteristic learning theory system through long-term theoretical exploration and teaching practice.

\section{2Training of Innovative Spirit and Practical Ability in Junior High School Teaching 2.2.1 Connotations of Innovative Spirit and Practical Ability}

Innovative spirit refers to thinking ability of proposing new methods and opinions by comprehensive utilization of available knowledge, information, skills and methods, as well as the will, confidence, courage and wisdom of inventing, creating and reforming. It's a kind of spirit that is brave to abandon old ideology and old things to create new ideologies and things. Practical ability is principally about hands-on ability or operational ability. Such orientations not only narrows the scope of practical ability but also consciously excludes other types of practical ability, thus intangibly causing the situation of training hands-on ability in an isolated way. Practical ability mentioned in this paper covers all abilities required in practice (observation ability, ability of information searching, expression ability, communication ability and experiment ability).

\subsubsection{Innovative Spirit, Practical Ability and Junior High School Mathematics Teaching}

Given characteristics of the mathematics discipline, innovative spirit can be used to guide two aspects while being confused with new problems and new knowledge: on the one hand, the transition period from primary school to junior high school; on the other hand, the mathematics learning process in the entire junior high school. We can train students' "thirst for knowledge, curiosity, exploration interest, persistent pursuit of the truth, sensitivity to new and foreign things, and unswerving spirit of discovering, inventing, reforming, opening up and being enterprising" (1) The junior high school mathematics experimental textbooks published by Phoenix Science Press strengthen close connections between mathematics and real life. The model of "question situation-mathematical model—explanation and application" makes dull mathematical knowledge become interesting and useful, and provides many opportunities for children to observe, guess, think, operate, verify, explore independently and cooperate and communicate. Besides, it allows multiple neural analyzers to work together, can accelerate new knowledge absorption, internationalization and restructuring with original knowledge, enhances learning efficiency and helps with training of students' practical ability.

\section{Practice Studies on Innovative Spirit and Practical Ability Training in Junior High School Mathematics Teaching}

\subsection{Practice Studies on Innovative Spirit Training}

The key to training students' innovative spirit lies in how to train students' interest in mathematics. For junior high school students, the saying of interest being the best teacher is of greater practical significance. How to train students' innovative spirit and stimulate their learning interest requires teachers to guide students step by step in the teaching process.

\subsubsection{Creating Independent Learning Situation}

Creating independent learning situation can help students give full scope to their innovation potential. It not only requires students' own efforts but also teachers' instruction. Only with joint efforts of students and teachers can students train their interest under independent learning framework. First of all, teachers need to transform their roles and update old traditional concepts. They need to become participants and guides in the teaching rather than imparting knowledge and leading. An equal and harmonious new-type student-teacher relation shall be adopted to replace traditional "absolute authority of teachers". Teachers shall become partners of students. "Teachers shall pay attention to students' psychological and physiological conditions as well as their experience foundation for learning; teaching activities shall be close to students' practice as much as possible. Teachers shall teach in accordance with their aptitude and make the best use of the circumstance with layered teaching objectives so that students with a poor foundation can keep up , study independently and pleasantly in favorable environment, and show full interest in learning”. 
Transformation to the new role of teachers is the first step to train students' learning interest and their innovative spirit. Second, teachers shall encourage students to love learning. In class, teachers shall create a learning space that can stimulate students' interest and innovation potential as much as possible. Once students have a question, they can ask without scruple. Interaction shall be conducted between students and teachers. Students will take intense interest in the current course if they are praised by teachers after asking a question. In future study, they will ask questions more proactively. In this way, both class efficiency and teaching quality can be further improved.

\subsubsection{Building Pleasant Teaching Atmosphere}

To build pleasant teaching atmosphere in class requires students to change traditional serious teaching style, activate class atmosphere, narrow the distance with students, encourage students to ask more questions, and answer them actively. When students suddenly turn to similar triangles to build other graphics from nervous and complicated similar proving, teachers shall encourage them to use their imagination and pacify the intense learning atmosphere. while guaranteeing class discipline, teachers shall guide students to be divided into groups, thus fully building a pleasant atmosphere and arousing students' interest in learning. By doing so, the class teaching efficiency will be naturally and prominently enhanced.

\subsubsection{Cultivating Students' Sense of Success}

In a relaxing teaching context, students study on their own mainly through self-study and communication, focusing on communication. Concerning junior high school students' characteristics, they particularly care about teachers' approval, especially approval of their homework, performance and behavior. Usually teachers' few words of encourage will enable students to study hard for a long time. teachers need to cultivate students' sense of success through their proactive thinking and expression, and train their innovative initiative. Teachers shall praise students without being stingy. Any desirable and right word and deed of students are worth affirmation and a pat on their back. They shall not be negated completely just for a minor mistake. Students will work harder with a sense of success, thus keeping thinking and innovating. Full cultivation of students' sense of success will help strengthen students' initiative in innovative ability training. Students of different personalities and characteristics shall be instructed separately. Under the prerequisite of not making students become arrogant, teachers need to make the most of circumstances, teach based on students' own aptitude and make students give better scope to their learning initiative and enthusiasm.

\subsection{Practice Studies on Practical Ability Training}

In mathematics teaching, students' life practice shall be combined to make students "comprehend" that mathematical knowledge comes from life and in turn serves life. Students shall be taught to operate in practice, observe life with a mathematical view and solve practical problems with mathematical knowledge.

\subsubsection{Constructing Effective Problem Contexts}

We usually incidentally separate learning from life during our teaching, especially so in mathematics. Letting students face problem contexts related with their life experience as much as possible is the primary condition for students to truly conduct "activity-based" study. For instance, after studying interest, students shall be required to go to the bank to learn about interest and interest tax knowledge, and help their parents calculate interest and interest tax. Students shall consolidate and apply what they learn in practice and amid entertainment.

\subsubsection{Encouraging Reasonable Partner Study}

At present, learning groups in class teaching are usually used for students to exchange answers or for teachers to go through the formality of activity-based teaching. Grouping carries the trace of the teachers' "administrative order". To change such situation, students with different interests and different learning types can be grouped through unfixed and non-unified forms according to different learning contents. Teachers shall be ready to receive the invitation of any group any time in class. They shall regard themselves as equals and partners of students. Before class, teachers shall focus on how to arrange learning groups, how to cooperate with division of labor, how to utilize learning resources and how to leave time and space for students who like self-directing. For 
instance, while teaching "multiplication application and common quantitative relations", teachers can design a series of practical assignments. Students can investigate prices of vegetables and fruits on the market, learn about the price of each kilo for five to ten vegetables and fruits through market survey, inquiry and personal purchase, etc., and respectively calculate prices for 2 kilos and 3 kilos......They can look up in materials, study as a group and ask parents. Students are willing to participate in such practical activities and desirable learning effect has been achieved.

\subsubsection{Advocating Diversified Self-Evaluations}

Self-evaluation is usually covered up by evaluation of teachers and students in class teaching. Many students who are initially curious about learning and desire to develop and perform gradually show weakened enthusiasm and curiosity about learning as they go to a higher grade. One probable reason is that students' self-criticism and self-evaluation are gradually placed in a minor position. In the process, students either form a kind of obedience psychology that depends on external evaluation of teachers, parents or classmates or a kind of rebel psychology that blindly refuses any external evaluation. Great advocacy of students' self-evaluation in class teaching one the one hand makes students take responsibility for their learning results and on the other hand trains students' non-intelligence factors. Multiple self-evaluation forms can be adopted for higher-grade students, including self-layout of the examination paper, self-test, self-scoring and mutual test, etc. For instance, while studying "prime number and composite number", students can categorize them according to features of approximate numbers of natural numbers ranging from 1 to 12 . After independent categorization, students shall set scoring levels on their own, explain it and then self-evaluate their results based on others' evaluation. Teachers shall not be reluctant to "waste" time to let students explore because it is conducive to giving scope to students' innovative spirit and practical operation ability.

\section{Conclusion}

Practice and innovation are not only a step of class learning but also a learning method and awareness that run through the entire learning process. It's not only demonstrated in small classes but also extended to families and communities. Teachers shall let students try observing their surroundings from a mathematical perspective and live their life with mathematical activities. Incorporation of "practical activities" into disciplines can turn passive learning to active learning, and proactive development will improve students' innovative awareness. Practice is the foundation for innovation. The emphasis on innovative spirit and practical ability training in junior high school mathematics teaching is a fundamental necessity for students' personal growth and development.

\section{References}

[1] XU Yi. A Study on Students' Innovative Ability Training in Junior High School Mathematics Teaching [D]. Hunan Normal University, 2011.

[2] GAO You. A Study on Students' Innovative Ability Training in Junior High School Mathematics Teaching [D]. Suzhou University, 2008.

[3] LUO Shimin. Practice and Thoughts on Innovative Ability Training in Junior High School Mathematics Teaching [J]. China Science and Technology Information, 2010, (15).

[4] SONG Xiaohong. Primary Exploration of Hands-on Practice in Mathematics Class and Coping Strategies [J]. Teaching Research for Primary and Middle Schools, 2011, (05).

[5] WANG Kang. On Several Practices of Training Students' Innovative Ability in Mathematics Teaching [J]. New Curriculum (Junior High School Edition), 2006, (Z1). 